technique of reassociation, or hybridisation as it is called when the DNA chains are from different organisms, or involves an RNA chain, has led to a new understanding of the nature of the base sequences, their repetition and their location, in the very long DNA molecules thought to comprise each eukaryotic chromosome. In Busch's volume seven articles refer to various aspects of this problem and Strauss makes useful comparisons with the genomes of bacteria and viruses. The most thoroughly understood sequence is that coding for ribosomal RNA (Choi, Nazar and Busch), but the article on the fine structure of the site of its transcription, the nucleolus, may leave readers in a confused state because of the lack of a suitable schematic diagram and because of the variation in the terminology used for the different zones.

Second, in 1960, Barski discovered the spontaneous hybridisation of different cell types. Cell fusion has been called "the new gift to biology" and the reasons will become clear from Sidebottom's excellent article on heterokaryons. Cell fusion is the analogue of gamete fusion and Kucherlapti, Creagen and Ruddle describe its use in genetic analysis of somatic cells. The genetic content of the nucleus can also be studied by implantation into eggs and Gurdon summarises his elegant experiments which show that cell differentiation is not accompanied by loss of, or permanent alteration of, genes.

Five articles, including a lucid, basic introduction by Arrighi, provide a comprehensive survey of mammalian metaphase chromosomes and their recently discovered banding patterns. There are, however, numerous texts on these topics and the article showing clinical pictures of the effects of chromosome imbalance could have been omitted to help reduce the high cost of these volumes. Substantial articles deal with heterogeneous and other nuclear RNAs, nuclear proteins and DNA polymerases, and DNAdependent RNA polymerases. Franke and Scheer, and Kasper, have contributed extensive and detailed articles on the nuclear envelope and their enthusiasm is evident from the number of recent results added in proof. There are also excellent chapters by Edström and by Hennig on polytene chromosomes. An aspect of chromosome structure, other than the base sequence, is the way in which the DNA molecule is folded up in association with proteins, and Solari skilfully steers us through the complexities, but unfortunately the book is already too out of date to include exciting new results on $\nu$-particles, nuclease-protected fragments and so on.

The Cell Nucleus contains most of the relevant material conveniently collected in one place (in addition to those mentioned the volumes include a number of other valuable articles) and will be an important source of references. Some subjects are, however, controversial-for example, the nature of heterochromatinor complex-like repetitious DNA and its possible functions-and readers no doubt will feel a real need to consult the dozen or so annual reviews where related and sometimes more lucid articles can be found. Most chapters are very specialised and won't be suitable for undergraduate study.

There is no doubt that the books, which seem at first sight formidable in their bulk, would have benefited greatly from a good historical introduction outlining the important discoveries and showing how articles were chosen so as to fit into the general scheme.

Howard G. Davies

\section{Plants and salts}

Ion Transport and Cell Structure in Plants. By David Clarkson. Pp. xi+ 350. (European Plant Biology Series.) (McGraw-Hill : London and New York, April 1974.) £6.95.

THIS is the first book on plant-salt relations I have seen which takes full account of the advances in the subject which have been made in the last 10 years. In this respect it makes some recent American texts look distinctly old fashioned.

Here the undergraduate, for whom the book is intended, can read about isotope washout curves, the electrochemical approach and the chemiosmotic hypothesis, topics which have not been seen together before in a book of this type. The first six chapters are concerned with the cellular level and include an excellent chapter on the cell membrane. To illustrate the principles Dr Clarkson frequently refers to the alga Hydrodictyon africanum as a model; a good idea for an undergraduate text.

The second half of the book deals with the salt relations of the higher plant and in particular the root. It is not as well set out or as well written as the first half which one feels would make an excellent book on its own.

There are one or two errors in the text which might confuse the undergraduate such as the one on page 227 where in a discussion about the structure of the endodermis the reader is referred to a figure which turns out to be a scanning electron micrograph of a xylem vessel. Despite these blemishes Dr Clarkson is to be congratulated on his bold modern approach.

D. J. F. Bowling
New from Addison-Wesley Advanced Book Program

S. S. PENNER and L. ICERMAN University of Califomia. San Diego ENERGY (3-vol. set of lecture notes) Vol. 1: Demands, Resources, Impact, Technology, and Policy

The authors begin with an assessment of energy demands and resource evaluation and note uncertainties in both methodology and fact. The careful reader, who examines all of the information, is left with insight and appreciation of the difficulties involved in energy-demand projections and resource evaluations.

1974, xx, 473 pp., hardbd.

ISBN 0-201-05560-0, $£ 8.00$

paperbd. ISBN 0-201-05561-9, £4.70

Vol. 2, Spring 1975: Non-nuclear Technologies

Vol. 3, Spring 1976: Nuclear Energy and Energy Policies.

Detailed leaflet available

HELLMUT J. JURETSCHKE

Polytechnic Institute of New York

Crystal Physies*

Macroscopic Physics of Anisotropic Solids

Contains a unified discussion of the conse quences of including the tensor anisotropy of matter in various areas of macroscopic physics. The physics of each topic is introduced brietly; the more common applications of anisotropy are reviewed, without aiming to achieve completeness. More detailed atten tion is given to applications not usually treated. Also included are extensions to new anisotropic effects of interest to researchers The accompanying mathematics is developed as informally as possible; stress is laid on simplification, short-cuts, and intuition applicable in each instance. Generally, fifteen to twenty problems conclude each chapter. 1974. xvi, $220 \mathrm{pp}$., hardbd.

ISBN $0-805-35102-7$, £10.75, paperbd.

ISBN 0-805-35103-5, £6.90

MODERN PHYSICS MONOGRAPH SERIES, NO. 3

N. BOGOLUBOV, A. A. LOGUNOV, 1. T. TODOROV

\section{Introduction to}

Axiomatic Quantum Field Theory*

Authorized translation from the Russian manuscript by Stephen A. Fulling and Ludmila G. Popova)

Provides a systematic, self-contained, and modern exposition of axiomatic quantum field theory. It does not require much preliminary knowledge of either mathematics or quanturn field theory and leads the reader to the present-day frontiers of the subject. Spring 1975, about $700 \mathrm{pp}$.

ISBN 0-805-30982-9, approx. £16.50 MATHEMATICAL. PIHYSICS MONOLRAPH SERIES. No. 18

*W. A. Benjamin, Inc title

Addison-Wesley Publishers, Ltd.

West End House Advanced Book Program 11 Hills Place Reading, Mass. 01867 London U.S.A 